\title{
Analysis of Student-at-Risk of Dropping out (SARDO) Using Decision Tree: An Intelligent Predictive Model for Reduction
}

\author{
Maricel A. Timbal
}

\begin{abstract}
The advancement of the country is exceptionally reliant on the education of its citizens, which is an incontestable truth of the worldwide perspective. Education assumes a focal part of developing an individual to become a productive citizen and is the most important factor contributing to the progress of the nation. However, children in developing countries have denied their right to education by dropping out for different reasons. Student-At-Risk of Dropping Out commonly known as SARDO is a term coined by the Philippines' Department of Education, defined as, a student who is likely to become a candidate to drop out. Philippine Statistics Authority had conferred that there is a total of 36,238 people ages from six to twenty-four who are out-of-school. This poses a predicament if this will continue without even attempting to intervene or at least reduce it gradually, to the governing body (DepEd) and ripple its effect to the entire country. In this paper, a classification data mining technique such as decision tree was used to generate a rule-based classifier. Based on results, there were three extracted rules from the decision tree generated using partykit and rpart libraries as a predictive model, a basis for forecasting who among the enrolled students will be a dropout. The first rule is, if a student has an experience being retained from previous grade level/s, he/she is more likely to drop. The second is, if he/she has not experienced retention but his/her number of siblings is greater than six, most probably he/she will drop from school. The last rule is if a student has not experienced retention nor has greater than six siblings, but his/her general average of previous grade level is fairly satisfactory and satisfactory, then he/she will probably stop from schooling. Having this intelligent predictive model, the educational institution with its stakeholders can now have a proactive measure on addressing to reduce the inflation of dropout rate of which is the sole purpose of why this study was conducted.
\end{abstract}

Index Terms-Dropout, data mining, decision tree, rule-based.

\section{INTRODUCTION}

The advancement of the country is exceptionally reliant on the education of its citizens, which is an incontestable truth of the worldwide perspective [1]. Education assumes a focal part of developing an individual to become a productive citizen; and is the most important factor contributing to the progress of the nation. However, children in developing countries have denied their right to education through dropping out for different reasons. Student-At-Risk of Dropping Out commonly known as SARDO is a term coined by the Philippines' Department of Education, defined as, a student

Manuscript received November 20, 2019; revised April 24, 2019.

Maricel A. Timbal is with the Department of Education, Division of Davao del Norte, Philippines (e-mail: maricel.timbal@ deped.gov.ph). who is likely to become a candidate to drop out. National Center for Education Statistics defined dropping out as discontinuing the program and leaving school before graduation without achieving a diploma. Dropping out from school is not just a teacher adviser's issue because of the reason it will reflect his or her performance of how many students were promoted to the next grade level nor an issue of a dropout student, but it also affects the entirety of the nation. Hoff, et al. [2] supported this argument, stated that this issue impacts more than just the student who makes this decision, but it also affects his or her family, the community, and society as a whole. Campbell [3] studied the socioeconomic consequences of high school dropouts. He evidently displayed in his paper that there is a strong effect of dropout in the increase of socioeconomic disadvantages.

Chua [4], Chua [5] showed a Public Secondary School Exploratory Analysis that quantify the dropout rate from years 2013 to 2015 data. In it, Region XI landed on the thirteenth place among the regions with highest dropout rates in all three years. Whilst, Region II listed as the first in rank. In addition, Division of Davao del Norte had 23, 956 enrollees and a dropout rate of $3.25 \%$ in 2013; 26, 042 enrollees and a dropout rate of $3.16 \%$ in 2014; and 27, 128 enrollees and a dropout rate of $4.48 \%$ in 2015. In 2014, there is a decrease in dropout rate but on the following year - 2015, the line is started to climb because of the full implementation of the Republic Act No. 10533 entitled "An Act Enhancing the Philippine Basic Education System by Strengthening Its Curriculum and Increasing the Number of Years for Basic Education", otherwise known as the "Enhanced Basic Education Act of 2013" - adding two years to a 10-year acquisition of basic education; it is also commonly known as "K-12 program". Lisay [6], Mateo [7] posted a news that there were an estimated 400,000 junior high school completers have dropped out with a dropout rate of $27 \%$. Philippine Statistics Authority had conferred on [8] that there is a total of 36, 238 people ages from six to twenty-four who are out-of-school. This poses a predicament if this will continue without even attempting to prevent or at least reduce it gradually, to the governing body (DepEd) and ripple its effect to the entire country. Martin [9] discussed that UNESCO warns Southeast Asian countries including the Philippines to take urgent measures to lessen the number of out-of-school youths and enroll them to avoid economic consequences in the future such as losing billions of dollars and a decrease of the percent of gross domestic product (GDP).

There are few empirical pieces of research had set its focus on the issue about dropouts but only a little research in 
number applied educational data mining set in the Philippines. This paper targets to address this gap. It aims to analyze the data set of SARDO's from the Division of Davao del Norte specifically the senior high school students of Kapalong National High School who had dropped out from school using the decision tree and then convert to rule-based supervised learning to provide a predictive model to forecast who, among the enrolled students, might drop and intend to leave the school in relation to the given combination of attributes which had caused a student to drop. Moreover, with the findings it provides, this study will redound to the following beneficiaries: (1) Policy maker could amend if there is already an existing policy governing on funding Department of Education solely for the dropout and Department of Social Welfare and Development to encourage out-of-school youth to go back to school and continue their studies; (2) Department of Education Officials could make this as a guide in making a strategic plan towards intensifying Drop Out Reduction Program (DORP); (3) School Administrators will be encouraged to create an action plan for reducing the dropout rate and give much attention to strengthening "Oplan Baling" program; (4) Teachers will be notified of the predictors causing SARDO to drop and exercise early remedial session; and (5) Students will be given emphasis to manifest their right for education.

\section{THEORETICAL FRAMEWORK}

\section{A. Student Dropout Factors}

Student dropout is prevalent in all educational institution that is the reason why numerous of empirical studies attempt to develop efficient methods for prediction enabling to reduce risk and manage to adopt proactive measure [10].

In Doll et al. [11] study, they had made a comparative analysis of seven nationally representative studies to understand why students drop out of high school. They categorized it into three factors that affect the student's decision; these are: (1) Push factors include school-consequence on attendance or discipline; (2) Pull factors include out-of-school enticements like jobs and family; and (3) Falling out factors refer to disengagement in students not caused by school or outside pulling factors. The first two factors are extrinsic, and the latter is intrinsic.

In the United States of America, a research conducted by Burrus et al. [12] about dropping out of high school came up with four categories of factors affecting them to drop out; these are (1) Demographics include a student comes from low-income family, he/she is a member of racial or ethnic minority group, male, and older than the average student in their grade; (2) Performance include lack of credits earned, poor attendance, and poor grades especially in core courses; (3) Self-identified factors about include class not interesting, lack of engagement with school, test too difficult, and poor attendance; and lastly, (4) Self-identified factors about others include adults did not expect them to perform in school and parents not involved in education. Another study made by Fall et al. [13] was conducted in the same country about dropouts suggested that social contextual includes family support, teacher support, and peer support; self-system includes perceived identification with school and perceived control by the extent to which it meets or ignores, as coined by Fan et al. [14] as student's educational expectations; and school engagement mediates the relation between self-system process and student outcomes, are variables contribute to decisions to drop out. Moreover, Eck et al. [15] cited that chronic absence is one major problem in schools. School climate impacted student chronic absence rate and eventually leads to dropping out. In 2017, Hughes et al. [16] investigated the effect of grade retention in elementary school found out the implication of the students who were retained in the elementary grades would be likely to leave school than their promoted peers.

In Zimbabwe, a research conducted by Chinyoka [17] figured out that poverty in household, child labor or household chores, broken families, poor supervision by parent, involvement in bad company or peer pressure, drug abuse, and malnutrition and health-related issues, low self-motivation [18] and lack of interest in education, are variables of dropping out.

In Turkey, Alkan [19] had found out that the predictors are non-academic factors. Students' dropout intention relates to intrinsic indicators such as school membership, loneliness, and coping strategies.

In Lebanon, Al-Hroub [20] explored the perspective of school dropout's dilemma, on his findings, socioeconomic status, school curriculum and services, family involvement, and domestic laws governing the participation of Palestinian refugees.

In Brazil, Fernades et al. [21] identified the main factors influencing secondary dropout. These are all intrinsic factors significant to influence the decision to drop out, such as difficulties faced with courses (subjects), desire for different school, the perception of better job opportunities, and importance assigned to school choice.

In India, Hegde [22] reduced the fifty-one (51) attributes affecting students to drop out. A multidimensionality of dataset was reduced to seven (7) through Principal Component Analysis. These were financial instability, an ability to cope with advanced courses (subject), university examination policy, lack of attendance, lack of motivational factor, and policy matter of the institution. On the other hand, Sharma et al. [23] cited that the reason why the student will likely to drop from school is the aggression they had experienced whether in face-to-face violence or electronic bullying.

In Canada, a study conducted by Ricard et al. [24] revealed that there is a role of parent and teacher to support basic psychological needs of the student. Other significant factors are reciprocal friendships and academic motivation considerably evident contributing to the prediction of dropping out.

\section{B. Data Mining Concept}

Data mining is a process of extracting actionable information from a large scale of data through identifying valid, interesting, novel, useful, and ultimately understandable patterns hidden in the data [25], [26]. Through data mining techniques it can yield the benefits of automated prediction of trends and behaviors, or automated 
discovery of previously unknown patterns [27]. Data mining is also popularly known as Knowledge Discovery from Data (KDD) [28]. It consists of an iterative sequence of the following steps: (1) Data cleaning, (2) Data integration, (3) Data selection, (4) Data Transformation, (5) Data mining, (6) Pattern evaluation, and (7) Knowledge presentation.

\section{Related Work}

TABLE I: COMPARATIVE TABLE OF DATA Mining TECHNiQues IN SIMILAR STUDIES

\begin{tabular}{|c|c|c|c|}
\hline Year & Place & Study & $\begin{array}{l}\text { Data Mining } \\
\text { Technique } \\
\text { Used }\end{array}$ \\
\hline 2013 & India & $\begin{array}{l}\text { Students' Dropout Risk } \\
\text { Assessment in Undergraduate } \\
\text { Courses of ICT at Residential } \\
\text { University - A Case Study [29] }\end{array}$ & ID3 andJ48 \\
\hline 2013 & Brazil & $\begin{array}{l}\text { Prediction of School Dropout } \\
\text { Risk Group Using Neural } \\
\text { Network [30] and An } \\
\text { Intelligent System for } \\
\text { Prediction of School Dropout } \\
\text { Risk Group in Higher } \\
\text { Education Classroom based on } \\
\text { Artificial Neural Networks [31] }\end{array}$ & $\begin{array}{l}\text { Fuzzy-ARTM } \\
\text { AP Neural } \\
\text { Network }\end{array}$ \\
\hline 2013 & Mexico & $\begin{array}{l}\text { Predicting School Failure and } \\
\text { Dropout Using Data Mining } \\
\text { Techniques [32] }\end{array}$ & $\begin{array}{l}\text { C4.5, J48, and } \\
\text { SimpleCart }\end{array}$ \\
\hline 2015 & India & $\begin{array}{lrr}\text { Students } & \text { Dropout } & \text { Factor } \\
\text { Prediction } & \text { Using } & \text { EDM } \\
\text { Techniques [25] } & \end{array}$ & $\begin{array}{l}\text { C4.5, } \\
\text { SimpleCart, } \\
\text { and } \\
\text { ADTree }\end{array}$ \\
\hline 2015 & Colombia & $\begin{array}{lrr}\text { Student } & \text { Dropout } & \text { Predictive } \\
\text { Model using } & \text { Mining } \\
\text { Techniques [26] } & \end{array}$ & $\mathrm{J} 48$ and ID3 \\
\hline
\end{tabular}

As shown in Table I, there were five similar studies that had set its focus on dropout and are using data mining technique. Nonetheless, there was no study conducted in Southeast Asia of which was warned by the UNESCO of the negative implication to its economic status.

\section{OPERATIONAL FRAMEWORK}

Fig. 1 shows the architectural design of the study. The information being used in the study were gathered from the Guidance Counselor of Kapalong National High School. It is the home visitation form of all senior high school SARDO's. Guidance Office was the repository of all home visitation form duly filled in by teacher adviser after his/her visit to the house of the SARDO. After which, it was being encoded into a spreadsheet to be imported in RStudio. Scripting is then applied to produce a decision tree.

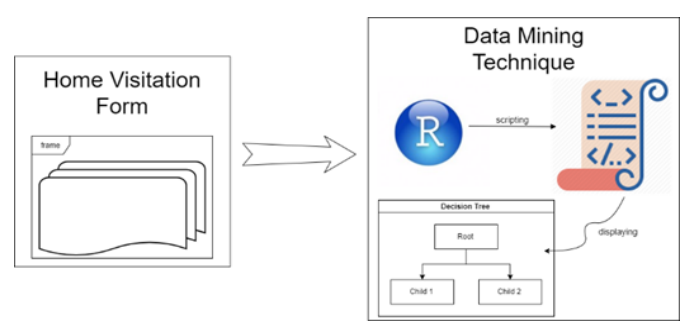

Fig. 1. Block Diagram for analyzing SARDO.

\section{A. Data Used}

As shown in Table II, the attributes of SARDO dataset were renamed for the reason of convenience in the scripting in RStudio. These eighteen attributes were taken from the actual home visitation form of the Department of Education and were preselected in relation to the student dropout factors evidently presented by related studies.

TABLE II: ATTRIBUTES OF THE SARDO DATASET

\begin{tabular}{|l|l|}
\hline \multicolumn{1}{|c|}{ Acronym } & \multicolumn{1}{c|}{ Description } \\
\hline GEN & Gender \\
\hline FEA & Father's Educational Attainment \\
\hline FOC & Father's Occupation \\
\hline MEA & Mother's Educational Attainment \\
\hline MOC & Mother's Educational Attainment \\
\hline LWNF & Living with non-family \\
\hline PITF & Position in the family \\
\hline NOS & Number of siblings \\
\hline FIN & Financial Status \\
\hline TOD & Type of Dwelling \\
\hline HOW & House Owned \\
\hline HOM & House Material \\
\hline DAFS & Distance away from School \\
\hline ETH & Ethnicity \\
\hline REA & Religious Affiliation \\
\hline GAPL & General Average of previous level \\
\hline XRET & Experience Retention \\
\hline DO & Drop Out \\
\hline
\end{tabular}

\section{B. Decision Tree Classifier}

A decision tree is a flowchart, with structure of tree, where the internal nodes represent validations on the attributes, the branches represent the outputs of the validations, and leaf nodes represent classes. The node in the upper part of the tree is known as the root node. To classify an "unknown" instance, the flow of the tree from the root and down, according to the values that have the attributes for each node, and when you reach a "Leaf node", the instance is classified according to class assigned by said node [33].

\section{SARDO Analysis}

As a first step, a sample was drawn of student data. The information was generated in an Excel file separated by commas (CSV) to have greater flexibility when exporting the data. It should be noted that this first sample contains sensitive information from Home Visitation Forms that the teacher adviser fills in at the time of visiting the SARDO of which the guidance counselor takes care of after the visit.

Once the data were loaded in RStudio, two partitions were made for the training data and testing data. Out of fifty-six (56) observations, thirty-eight (38) tuples were assigned to training data and the remaining eighteen (18) were assigned in testing data.

As shown in Fig. 2, XRET was the root of the tree. This means that if SARDO had already experience being retained in his/her previous grade level/s, it is most likely that he/she will drop from school. On the left subtree, GAPL is the child of XRET. This means that if SARDO, if he/she did not experience retention from previous grade level/s but has a fairly satisfactory scholastic record as general average of previous grade level (e.g. if SARDO is grade 11, then his/her grade 10 GAPL is what it means to previous grade level) attained, then it bears a significant implication to dropping out. Generated rules were extracted from the decision tree on Table III. 


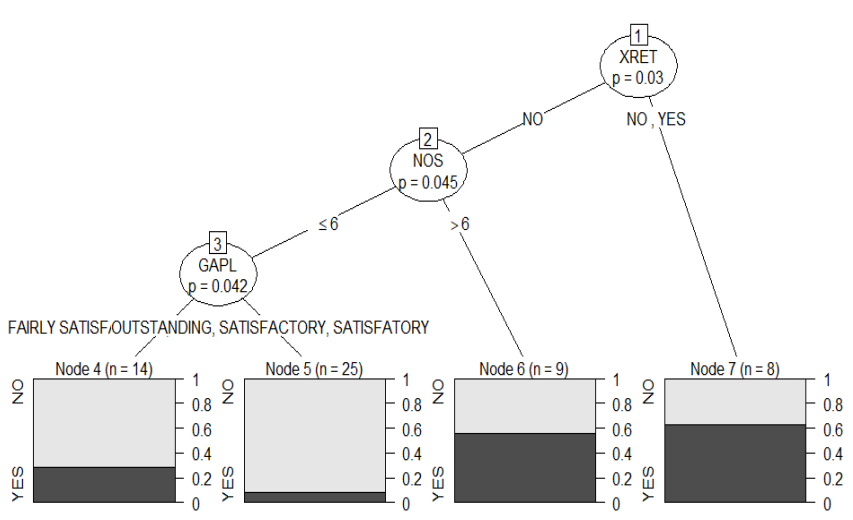

Fig. 2. Decision tree plot using partykit library.

Based on Fig. 3, NOS is the prime predictor. It says that if SARDO has more than six siblings, then he/she will likely to drop. However, if he/she has lesser than six siblings, GAPL is considered as the next predictor. It interprets that if his/her GAPL is either fairly satisfactory or satisfactory, and NOS is greater than 4 but less than 6 , then he/she will likely to drop. Otherwise, he/she will continue to study. On Table IV is the generated rules based from decision tree using rpart.

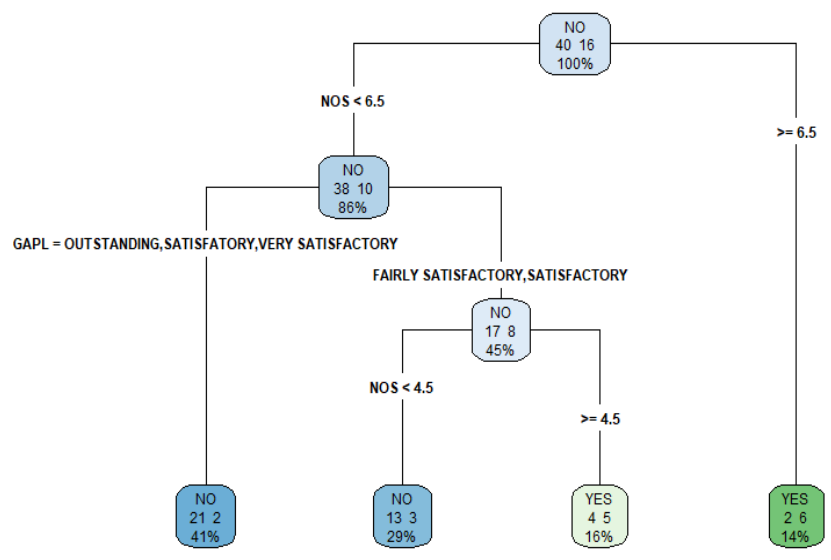

Fig. 3. Decision tree plot using rpart library [34].

TABLE III: GENERATED RULES FROM FIG. 2

\begin{tabular}{|c|c|c|c|}
\hline & RULE & $n$ & $C F$ \\
\hline 1 & $\begin{array}{l}\text { IF XRET }=\text { NO AND NOS }<=6 \text { AND GAPL }= \\
\{\text { FAIRLY SATISFACTORY, VERY } \\
\text { SATISFACTORY }\} \text { THEN DO }=\text { NO }\end{array}$ & 14 & $71.4 \%$ \\
\hline 2 & $\begin{array}{l}\text { IF XRET }=\text { NO AND NOS }<=6 \text { AND GAPL }= \\
\{\text { OUTSTANDING, VERY SATISFACTORY, } \\
\text { SATISFACTORY }\} \text { THEN DO }=\text { NO }\end{array}$ & 25 & $92 \%$ \\
\hline 3 & $\begin{array}{l}\text { IF XRET }=\text { NO AND NOS }>6 \text { THEN DO }= \\
\text { YES }\end{array}$ & 9 & $55.6 \%$ \\
\hline 4 & IF XRET $=$ YES THEN DO $=$ YES & 8 & $62.5 \%$ \\
\hline
\end{tabular}

The decision tree of training data as shown in Fig. 4, XRET was the root of the tree implies that it is the most significant factor after thirty-eight tuples were being processed. Five from it was classified as dropout. Furthermore, another condition is sprouted from the root which is the GAPL. It simply means that if SARDO is not a returnee but his/her GAPL is either from satisfactory or fairly satisfactory, then he/she will be a dropout.

The decision tree of testing data as shown in Fig. 5, NOS was the root of the tree. In here, testing data which has eighteen tuples happened to have a NO value in DO in all records. Upon cross-validation with training data, prediction says if SARDO is having more than 4.5 siblings, then he/she will likely to drop. Although there is no fractioned number of siblings, the value there is a result of analysis having a continuous data.

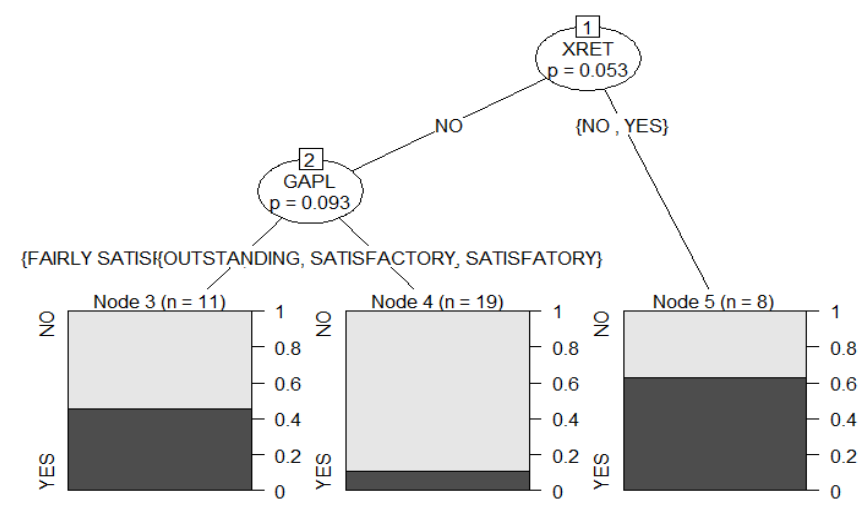

Fig. 4. Decision tree plot of the training data using partykit library.

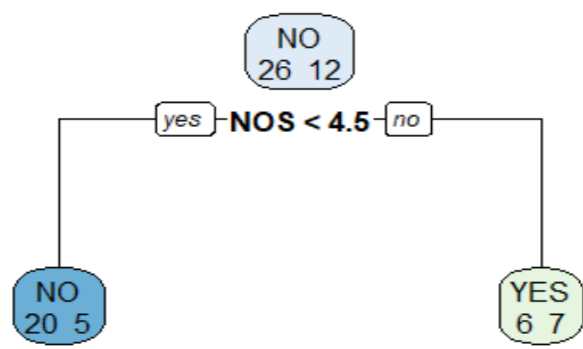

Fig. 5. Decision tree plot of testing data against training data as predicted using rpart library.

TABLE IV: GENERATED RULES FROM FIG. 3

\begin{tabular}{|c|c|c|c|}
\hline No. & $R U L E$ & $n$ & $C F$ \\
\hline 1 & $\begin{array}{l}\text { IF NOS < 6.5 AND GAPL }=\{\text { OUTSTANDING, } \\
\text { SATISFACTORY, VERY SATISFACTORY }\} \\
\text { THEN D0 = NO }\end{array}$ & 23 & $41 \%$ \\
\hline 2 & $\begin{array}{l}\text { IF NOS }<6.5 \text { AND GAPL }=\{\text { FAIRLY } \\
\text { SATISFACTORY, SATISFACTORY }\} \text { AND } \\
\text { NOS }<4.5 \text { THEN DO }=\text { NO }\end{array}$ & 16 & $29 \%$ \\
\hline 3 & $\begin{array}{l}\text { IF NOS }<6.5 \text { AND GAPL }=\{\text { FAIRLY } \\
\text { SATISFACTORY, SATISFACTORY }\} \text { AND } \\
\text { NOS }>=4.5 \text { THEN DO }=\text { YES }\end{array}$ & 9 & $16 \%$ \\
\hline 4 & IF NOS $>=6.5$ THEN DO $=$ YES & 8 & $14 \%$ \\
\hline
\end{tabular}

TABLE V: CONFUSION MATRIX

\begin{tabular}{|l|l|l|l|l|l|}
\hline \multicolumn{3}{|c|}{ Training Data } & \multicolumn{3}{|c|}{ Testing Data } \\
\hline & NO & YES & & NO & YES \\
\hline NO & 23 & 7 & NO & 14 & 4 \\
\hline YES & 3 & 5 & YES & 0 & 0 \\
\hline
\end{tabular}

TABLE VI: COMBINED RULES FROM BOTH

\begin{tabular}{l|l}
\hline No. & \multicolumn{1}{|c}{ Rule-based Classifier } \\
\hline 1 & IF XRET $=$ YES THEN DO $=$ YES \\
2 & IF NOS $>6$ THEN DO $=$ YES \\
3 & IF NOS $<6$ BUT >=4 AND GAPL = \{FAIRLY \\
& SATISFACTORY, SATISFACTORY $\}$ THEN DO = YES \\
\hline
\end{tabular}

Table $\mathrm{V}$ shows the misclassification of each partition. Training data has misclassified seven (7) records predicted to be NO (not dropout) but classified as YES (dropout). On the same manner, there are three (3) misclassified records. On the other hand, in testing data four (4) records were misclassified. There was no misclassified record as to YES (dropout) since the second partition was all contained NO (not dropout).

Based on results, Table VI was consolidated based on the generated rules from both decision tree using partykit and rpart, since the main objective of the study is to present an intelligent predictive model. This can be used as basis for 
teacher adviser to expect from their students who have the same attributes seen in the rule-based classifier compared to their student information sheet upon enrolment so that teacher adviser will not necessary practice home visitation and will not wait for the student to commit five (5) consecutive absences.

Furthermore, it implies that if student has an experience being retained from previous grade level/s, he/she is more likely to drop. If he/she has not experienced retention but his/her number of siblings is greater than or equal to six (6), most probably he/she will drop from school. If the student has not experienced retention nor has greater than or equal six (6) siblings but his/her general average of previous grade level is fairly satisfactory and satisfactory, then he/she will probably stop from schooling.

\section{CONCLUSION}

This study had presented an intelligent predictive model generated from DepEd's Home Visitation Form of senior high school students of Kapalong National High School.

Having this intelligent predictive model, educational institution with its stakeholders can now have a proactive measure on addressing to reduce the inflation of dropout rate of which is the sole purpose of why this study was conducted.

This study has a small size of observations due to the fact that senior high curriculum has just started its full implementation, and Kapalong National High School has just a population of nine hundred twenty-eight (928) as of school year 2017-2018, this pose for further study having greater observations to generate more reliable rule-based classifier that would represent the entire DepEd's SARDO. Moreover, the author recommends that this intelligent predictive model will be evaluated for its precision.

\section{REFERENCES}

[1] A. Latif, A. Chouhary, and A. Hammayun, "Economic effects of student dropouts: A comparative study," Journal of Global Economics, 2015.

[2] N. Hoff, A. Olson, and R. L. Peterson, "Dropout screening \& early warning," Student Engagement Project, University of Nebraska-Lincoln and the Nebraska Department of Education, Lincoln, 2015.

[3] C. Campbell, "The socioeconomic consequences of dropping out of high school: Evidence from an analysis of siblings," Social Science Research, p. 9, 2015.

[4] W. Chua. (July 16, 2017). DepED-SS DSWD and Census. [Online]. Available:

https://public.tableau.com/profile/wilson.chua\#!/vizhome/DepED-SS/ Story 1

[5] W. Chua. (December 16, 2016). Big data analytics: School dropout rates for grade 7 to grade 10. [Online]. Available: http://technology.mb.com.ph/2016/12/16/big-data-analytics-school-dr opout-rates-for-grades 7-to-10/.

[6] C. J. M. Lisay and A. B. Francia. (June 28, 2016). K12 prompts 27 percent dropout rate. [Online]. Available: http://www.philippinecollegian.org/2016/06/28/k12-prompts-27-perc ent-dropout-rate/

[7] J. Mateo. (June 14, 2016). Up to .4 M dropouts due to senior high. [Online]. Available: http://www.philstar.com/headlines/2016/06/14/1592807/400000-m-d ropouts-due-senior-high

[8] Out-of-School Children and Youth in the Philippines. (April 20, 2015). [Online]. Available: https://psa.gov.ph/content/out-school-children-and-youth-philippinesresults-2013-functional-literacy-education-and
[9] K. A. Martin, "UNESCO warns of economic consequences of rising number of out-of-school youths," The Philippine Star, August 2015.

[10] S. Rai, "Student's dropout risk assessment in undergraduate course at Residential University," IJCA International Journal of Computer Applications, vol. 84, no. 14, pp. 1-69, 2013.

[11] J. J. Doll, Z. Eslami, and L. Walters, "Understanding why students drop out of high school, according to their own reports: Are they pushed or pulled, or do they fall out? A comparative analysis of seven nationally representative studies," SAGE Open, pp. 1-15, 2013.

[12] J. Burrus and R. Roberts, "Dropping out of high school: prevalence, risk factors, and remediation strategies," ETS Research \& Development Educational Testing Service, 2012.

[13] A.-M. Fall and G. Roberts, "High School dropouts: Interactions between social context, self-perceptions, school engagement, and student dropout," National Institutes of Health Public Access, pp. 1-22, 2012.

[14] W. Fan and C. A. Wolters, "School motivation and high school dropout: The mediating role of educational expectation," British Journal of Educational Psychology, pp. 1-18, 2014.

[15] K. V. Eck, S. R. Johnson, A. Bettencourt, and S. L. Johnson, "How school climate relates to chronic absence: A multi-level latent profile analysis," Journal of School Psychology, pp. 1-14, 2016.

[16] J. N. Hughes, Q. Cao, S. G. West, P. A. Smith, and C. Cerda, "Effect of retention in elementary grades on dropping out of school early," Journal of School Psychology, pp. 1-17, 2017.

[17] K. Chinyoka, "Causes of school drop-out among ordinary level learners in a resettlement area in Masvingo, Zimbabwe," Journal of Emerging Trends in Educational Research and Policy Studies, pp. 1-7, 2014.

[18] L. Paura and I. Arhipova, "Cause analysis of students' dropout rate in higher education," in Proc. 2nd World Conference on Business, Economics and Management, 2013, pp. 1-5.

[19] N. Alkan, "Humor, loneliness and acceptance: Predictors of university drop-out intentions," Procedia Social and Behavioral Sciences, pp. $1-8,2014$.

[20] A. Al-Hroub, "Perspectives of school dropouts' dilemma in Palestinian refugee camps in Lebanon: An ethnographic study," International Journal of Educational Development, pp. 1-14, 2014.

[21] N. D. S. Fernades, T. M. Soares, M. C. Nobrega, and A. C. Nicolella "Factors associated with dropout rates in public secondary education in Minas Gerais," Educacao e Pesquisa, vol. 41, no. 3, pp. 1-16, 2015.

[22] V. Hegde, "Dimensionality reduction technique for developing undergraduate student dropout model using principal component analysis through R package," in Proc. 2016 IEEE International Conference on Computational Intelligence and Computing Research, 2016, pp. 1-6.

[23] D. Sharma, J. Kishore, and N. Sharma, "Aggression in schools: cyberbullying and gender issues," Asian Journal of Psychiatry, pp. 1-13, 2017.

[24] N. C. Ricard and L. G. Pelletier, "Dropping out of high school: The role of parent and teacher self-determination support, reciprocal friendships and academic motivation," Contemporary Educational Psychology, pp. 1-9, 2016.

[25] A. Pradeep, S. Das, and J. J. Kizhekkthottam, "Students dropout factor prediction using EDM techniques," in Proc. 2015 International Conference on Soft-Computing and Networks Security, 2015, pp. 1-7.

[26] Y. Amaya, E. Barrientos, and D. Heredia, "Student dropout predictive model using data mining techniques," IEEE Latin America Transactions, vol. 13, no. 9, pp. 3127-3134, 2015.

[27] An introduction to data mining: Discovering hidden value in your data warehouse. [Online]. Available: http://www.thearling.com/text/dmwhite/dmwhite.htm.

[28] J. Han and M. Kamber, Data Mining: Concepts and Techniques, 2nd ed., San Francisco, CA: Morgan Kaufmann Publishers, 2006.

[29] S. Rai and A. K. Jain, "Students' dropout risk assessment in undergraduate courses of ICT at Residential University - A case study," International Journal of Computer Applications, vol. 84, no. 14, pp. 1-6, 2013.

[30] V. Martinho, C. Nunes, and C. R. Minussi, "Prediction of school dropout risk group using neural network," in Proc. the 2013 Federated Conference on Computer Science and Information Systems, 2013, pp. 111-114.

[31] V. Martinho, C. Nunes, and C. R. Minussi, "An intelligent system for prediction of school dropout risk group in higher education classroom based on artificial neural networks," in Proc. 2013 IEEE 25th International Conference on Tools with Artificial Intelligence, 2013, pp. 1-8. 
[32] C. Marquez-Vera, C. R. Morales and S. V. Soto, "Predicting school failure and dropout by using data mining techniques," IEEE Journal of Latin-American Learning Technologies, vol. 8, no. 1, pp. 1-8, 2013.

[33] I. Witten and E. Frank, Data Mining: Practical Machine Learning Tools and Techniques with Java Implementations, San Francisco: Morgan Kaufmann Publishers, 2000.

[34] S. Milborrow. (2016). rpart.plot: Plot rpart Models. An Enhanced Version of plot.rpart. [Online]. Available: http://CRAN.R-project.org/package=rpart.plot

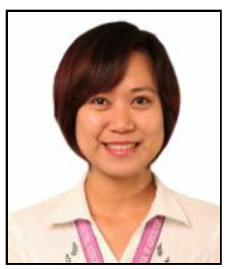

Maricel A. Timbal is a senior high school teacher of Kapalong National High School in the Division of Davao del Norte.

She's been teaching since 2008 in STI Tagum. She teaches office productivity, computer programming of the following languages/framework; java, jsp, php (with MySQL), .net, C\#, android; data structure (with java programming); and systems analysis and design. In 2014, she transferred to Kapalong College of Agriculture, Sciences and Technology as a program coordinator of bachelor of science in information technology. In the advent of the full implementation of K-12 curriculum in the Philippines, she then transferred to the Department of Education teaching ICT related courses. In her ten years' teaching period, she finds her profession a noble one influencing young individuals to be responsible citizens. In the place where she lives, ICT is not fully realized that is why she remains to teach in a rural place to uplift their being as to be globally competitive. 